\title{
Axiological aspects of foreign language teachers' preparation for primary foreign language education
}

\author{
Natalya Galskova ${ }^{1, *}$ and Zinaida Nikitenko $^{1}$ \\ ${ }^{1}$ Moscow Region State University, 24, Vera Voloshina str., 141014, Moscow region, Mytischi, Russia
}

\begin{abstract}
The article outlines axiological basis of professional training of English teachers, capable to develop communicative, cognitive and moral development of junior schoolchildren when they master a new language and facts from a different culture. The article refers both to the history of methodological research, in which the issues of the formation of professionally significant skills of a foreign language teacher were studied, and to the modern problems of the formation of the teacher's personality and his readiness for pedagogical activity. The article examines linguistic values and substantiates a new goal of professional training of a future foreign language teacher for the primary stage of secondary school, taking into account the priority of his spiritual ability and recognition of professionalism as its fundamental characteristic. The authors associate the formation of professionalism with the disclosure of the personal potential of the future teacher, which is an integrative phenomenon, the components of which are the basis for determining the new content of teacher training as a person capable of realizing the educational and developmental potential of primary foreign language education.
\end{abstract}

\section{Introduction}

Russian methodological science has always sought to create an ideal "image" of the personality of a foreign language teacher (FL). But the explicitly expressed interest of the methodologists in the personality of the FL teacher is noted only in the second half of the last century, which was primarily associated with the intensive and purposeful development of the professionogram of the FL teacher as the first systematic and complete vision of professionally significant skills aimed at the teacher's implementation of his main labor functions. Subsequently, this generalized image was developed in the form of various instrumental and functional constructs (K.E. Bezukladnikov, E.N. Solovova, M.M. Makhmuryan, and others). Professionally significant knowledge, skills and abilities of a teacher are considered in the aggregate - in dynamic interaction and interconnection, i.e. in the system and, most importantly, in the context dimension [1].

Starting from the 70 s- 80 s of the last century, special attention is also paid to the teacher for primary foreign language education, the systematic presentation of the tasks of his

\footnotetext{
* Corresponding author: galskova@mail.ru
} 
professional and methodological training and the description of the totality of his professional knowledge and skills [4, p. 78-82.]. The theoretical foundations for the training of such a teacher were laid by Professor G.V. Rogova - the founder of the scientific school "Professional methodological training of a teacher of foreign languages", which was developed in the works of her students and followers (N.V. Yazykov, S.Ya. Romashin, E.N. Solovova, K.S. Makhmuryan, and others).

The specificity of the acquisition of FL by children was studied in 80-90s of the 20th century in a large-scale Russian project that experimentally proved the developing value of communicative teaching of a non-native language for preschoolers and primary schoolchildren on the basis of an activity-based approach to formulating goals, determining the content and technology of mastering a foreign language at an early age.

The process of introducing foreign language into the practice of primary school education was started in 1994 after this successful experiment, and since 2005, a compulsory subject "Foreign language" was included in the curriculum of primary school. Since that time, specialists are being trained who are able to teach foreign language to primary schoolchildren. Various works related to this subject area are published.

At the same time, it should be noted that, despite the studies that have been carried out defining the goals, content and technology of mastering the foreign language by primary schoolchildren in the context of the personal paradigm, as well as research in the field of improving the quality of the methodological training of the foreign language teacher, the effectiveness of primary education in the field of foreign language is rightly recognized by methodological community as insufficient. Therefore, the development, substantiation and practical implementation of the processes of mastering the foreign language by children in a personal developmental context necessitates updating the training of specialists who are able to design and manage the foreign language education of primary schoolchildren, i.e. to ensure their moral, speech, cognitive and communicative development in the process of mastering the FL as a means of communication and knowledge.

Moreover, in recent decades, there have been large-scale organizational, structural and substantive transformations in the social and humanitarian environment and in its important segment - the educational sphere, which have passed and are continuing under the sign of the increased importance of the personal factor. This circumstance made it relevant for the theory and practice of training students - future teachers of foreign languages to turn to the axiological dimensions of vocational education, semantically related to linguistic values and meanings and addressed to the system of value-semantic relations that determine the behavioral models of a person in conditions of speech and non-speech communication, including in the professional field.

The history of the domestic methodology of teaching foreign language testifies to the fact that for a long time these aspects were associated by methodologists only with educational goals and were on the periphery of the interests of methodologists. Unfortunately, even today, despite the fact that the theory of learning FL has recognized the relevance of going beyond the narrow framework of training in the field of linguistic education, in the field of "meaning", "content" and "values", and, as a result, increased the degree of "human dimension" of its main categories (the proof is its appeal to such personally significant categories as: "professional linguistic personality", "professionally significant foreign language communicative competence", "value-orientational worldview of the teacher", etc.), solving the problems of professional training of the future teacher of foreign languages is limited, as a rule, to the definition of a set of professionally significant knowledge, skills and abilities as components of professional competence without taking into account the axiological component of the latter and vocational education as a whole, i.e. without taking into account the student's attitude to the activities performed by him, both in the educational and in the professional environment. 


\section{Materials and Methods}

The system of training a foreign language teacher for the primary stage of teaching foreign languages at school requires special research, since it is at this stage that educational and developmental tasks are of particular importance. Their high-quality implementation is possible for such a professional teacher who possesses not only "technological" skill, but is also a moral and spiritually developed personality. The training of such a professional requires the solution of a number of important issues, which include, first of all, the following. What should be understood by the axiological dimension of the professional training of a foreign language teacher for the primary stage of school education? What personal qualities and properties of a foreign language teacher should become the value objects of professional, including linguistic, training? How should the spiritual and moral development of a foreign language teacher be ensured, capable of realizing the educational and developmental potential of the "Foreign Language" subject in primary education?

The search for answers to these questions is the main goal of the research. The axiological (V.V. Ryzhov), systemic (I.L. Bim) and activity approaches (A.A.Leontiev, I.A. Zimnyaya) were chosen as its methodological basis. Research methods included both theoretical (analysis and synthesis, induction and deduction) and empirical (observation, conversation with students and teachers) methods.

The starting point for the study was the provision that a pedagogical university have to prepare a specialist-teacher of foreign languages, capable and ready to implement the main educational goal of primary language education, namely: the development of a primary school student by means of the discipline "Foreign language". Moreover, as shown in the study by Z.N. Nikitenko [2], it is primarily about the development of personal qualities and speech, moral, educational and cognitive abilities of the pupil. It is these abilities that ensure the successful mastery of the pupil in a language that is foreign to him. This, in turn, gives reason to consider the communicative, moral and cognitive development of a pupil as a true linguistic value and, therefore, as the goal of primary foreign language education. In turn, the foreign language speech skills and abilities formed in the child are only a means of achieving this goal.

The practical achievement of this goal, as the dominant goal of primary education, determines the importance of training such a foreign language teacher who is able to ensure the development and upbringing of primary schoolchildren while mastering a new language and facts from a different culture. This means that this teacher's ability is based on the synthesis of his various personal qualities, social, special, psychological, pedagogical, linguodidactic and methodological competencies, which provide him with the opportunity to effectively use the entire system of means and resources in different areas of his activity: information and communication, social and labor, communication, management, teaching, psychological and pedagogical. At the same time, the axiological dimension of the process of forming the future teacher of the foreign language dictates the need to consider the student's personality not only as a subject of speech foreign language communication and a subject of pedagogical activity, but also as a product and carrier of a specific linguistic ethnoculture, as a subject of knowledge of a foreign language, facts of another culture and a different system of values at the same time, as a subject realizing his linguo-ethno-sociocultural identity, as a subject of morality and a subject of cognition [1]. It is the personality with all the differences in its definition in science that is today the main value of professional linguistic education. The acceptance of this fact explains the status of this education not only as social, but also as a personally significant phenomenon filled with subjective meaning and aimed at shaping a future specialist, of course, under the influence of the social environment, the characteristics of those social and linguo-ethno-cultural groups in which it enters into, value orientations. Being a complex integrative system, it is 
known to affect both the form and different levels of interaction between the social and the individual in the student's personality, and the specific form of his awareness of the world around him, his past, present and future, his social orientation, and the system of fixed moral attitudes.

Thus, the axiological orientation of the professional linguistic education of studentsfuture teachers, allowing actualization of the human and cultural significance in all phenomena and subjects of professional linguistic educational reality, both theory and practice, promotes the personality to the status of the main value of professional linguistic education. In this regard, it becomes obvious that when defining the goal and content of professional training of a foreign language teacher for primary school, it is necessary to refer to such categories as "the personal potential of a foreign language teacher" and "the personality of a professional foreign language teacher".

It is a known fact that the professionalism of any teacher always presupposes creativity in his pedagogical activity, and spirituality acts as the basis of this creativity as "an essential, integral and dynamic characteristic of a personality, expressed in transcendence, responsibility, freedom, meaning and love, perseverance and the ability to convince" $[5, \mathrm{p}$. 331]. Recognition of this provision filled with axiological ideas requires equipping the future primary school teacher of foreign language not only and not so much with psychological, pedagogical and methodological knowledge, skills and abilities correlated with the professionogram of his actions. Knowledge, skills and abilities are not the goal of professional training of a future teacher, but the most important means of developing his professional capabilities, qualities, abilities, a means of his self-making, first as a specialist and then as a professional, a tool for realizing his personal potential.

\section{Results}

The study of the questions posed in the study made it possible to establish that the personality of a foreign language teacher is a fusion of a socio-psychological and linguistic personality as two hypostases of the same socially-active human essence. And if a socio-psychological personality “... manifests itself against a wide background of the world of people, really existing (primary) things, objects, phenomena and actions ..., then the environment for the manifestation of a linguistic personality is a sociolinguistic, sign (secondary) environment by its nature, undoubtedly, nationally unique and, like a law, anthropo- and culturogenic" [6]. If a socio-psychological personality is its values, spirituality, needs and orientation, these are its attitudes and perceptions, including the facts and phenomena of culture, then the linguistic personality is its linguistic consciousness and cognitive consciousness, and in relation to FL - secondary linguistic consciousness and secondary cognitive consciousness.

The personality of a FL teacher is a personality which is rooted in his own linguistic culture, understands it, speaks his native language, but this does not interfere with his understanding of another and other languages. This personality is able to create conditions for the development of students' communicative and cognitive abilities, personal characteristics, their assimilation of knowledge about the culture of the studied language, the culture of their country, their region of residence, increasing their cognitive activity, creating positive motivation for them to study both foreign and native languages and cultures.

In the course of observing the activities of the FL teacher during the lessons in primary school, it was possible to establish that he clearly follows the methodological canons, but at the same time often does not take into account (and does not know how to take into account) the psychophysiological capabilities of children, their interests and needs, he is distinguished by spiritual deafness (lack of response to the needs of children, 
emotional unresponsiveness), and he shows a sense of responsibility, first of all, to the set standards (Educational standard, Model program for foreign language), to the people who set these standards and check their implementation (school management, methodologists). Such a teacher may be a good specialist, but his whole personality and his activities are not "tinged" with spirituality. This means that he is not characterized by a careful attitude towards children and spiritual freedom, a creative attitude towards pedagogical activity and an appeal to the values of love and goodness. He is not responsible for children, for their personal and civic development. But only a teacher filled with love for his pedagogical activity and for those for whom it is performed [5, p.336], i.e. a teacher who is distinguished by spirituality, can successfully solve complex problems of elementary language education. At the same time, spirituality expresses the level of his responsibility. It, of course, along with the teacher's creativity and reflexive ability, his openness to innovations, determines the quality of development, upbringing and teaching of elementary school students of the foreign language. However, from our point of view, it is spirituality that should be singled out as a basic value and a systemic feature of a teacher's professionalism. Professionalism is always based on a moral foundation, is characterized by methodological responsibility and is prompted by conscience as the leading motive.

Thus, we come to the obvious conclusion that professionalism should be recognized as a fundamental basic property of the personality of a FL teacher and, at the same time, as the highest category of the quality of his professional activity, which requires purposeful formation and cultivation. In turn, the formation and cultivation of professionalism should be associated with the disclosure of the personal potential of the future teacher.

This potential is made up of a set of different, but at the same time, interrelated components: spiritual and moral, epistemological, communicative, creative, actually professional (pedagogical) [5]. It seems that these components should become objects of pedagogical influence in the university. Thus, the spiritual and moral potential is nothing more than the student's moral values, which determine his awareness of his responsibility and transcendence. It is also his moral ability to distinguish and choose true values as the basis for his future teaching activities and professional life in general. This is his ability and desire to put himself in the place of others, to express empathy for the child, as well as possessing a positive, empathic attitude towards each student, the ability to empathize, to intellectual and emotional involvement in working with children.

The epistemological component is represented by professional knowledge, skills, abilities (a set of competencies), as well as the methodological worldview of the future FL teacher. The basis of their formation is the student's intellectual and professionally oriented abilities, which allow him to carry out (self)observation, (self)analysis, (self)assessment of the educational environment, the nature of his interaction with students, his ability to provide favorable conditions in the class/group for the study of language and facts of a foreign language culture, the level of motivation and ways to activate the personal capabilities of each pupil.

In turn, the communicative component is associated with the communicative qualities of the student's personality, which determine the success of his foreign language communication and mutual understanding with children, as well as with the achievement of the ability to communicate in $\mathrm{C} 1$ level of foreign language (in accordance with the European system of levels of language proficiency - CEFR) and the organization of interaction, including intercultural, in the "teacher - student" and "student - group" systems. Taken together, these qualities and abilities are designed to provide the so-called pedagogical speech communication, including in the FL. This interaction is based on the interrelated skills of listening (listening and hearing the student), as well as speaking and 
writing (carrying out educational, nurturing and evaluative foreign language speech activity).

As for the creative component, it determines the student's ability to create in his activities for teaching children a foreign language and fully reflects his motivational, cognitive, emotional and volitional spheres and the "I-concept" of his personality as a future FL teacher of primary school, capable of creating a favorable foreign language communication environment with the help of FL in the educational process, stimulating students to master the language as a means of communication and its creative use in various types of practical activities.

The creative component is in the most natural way associated with the professional component, since it goes into the area of the student's professional inclinations and preferences in the chosen pedagogical activity and always manifests itself in the level of proficiency in professional linguodidactic and methodological knowledge, skills and abilities (competencies). The skills included in the professional component of the student's personal potential form the basis of his professional "baggage" and are an important condition for his professionalism in the future. They will allow him to choose effective teaching and evaluative techniques and technologies, predict the possibilities of their use in a specific educational and linguo-ethno-socio-cultural context of professionally significant information, evaluate it from the point of view of the main provisions of multicultural linguistic education, concretize the educational goals and content of training in the field of foreign language to the real educational conditions and ethno-socio-cultural-individual characteristics of primary schoolchildren.

Thus, the key concepts of the system of professional development of the future teacher are "personality", "value", "teaching", "cognition", "activity", "culture", which are interrelated with each other and mutually conditioned, for example, the personality of the student and his value-semantic system, personality and its activities, activities and teaching, teaching and cognition, teaching and linguoculture, value and culture, development and culture, etc. (see Figure 1).

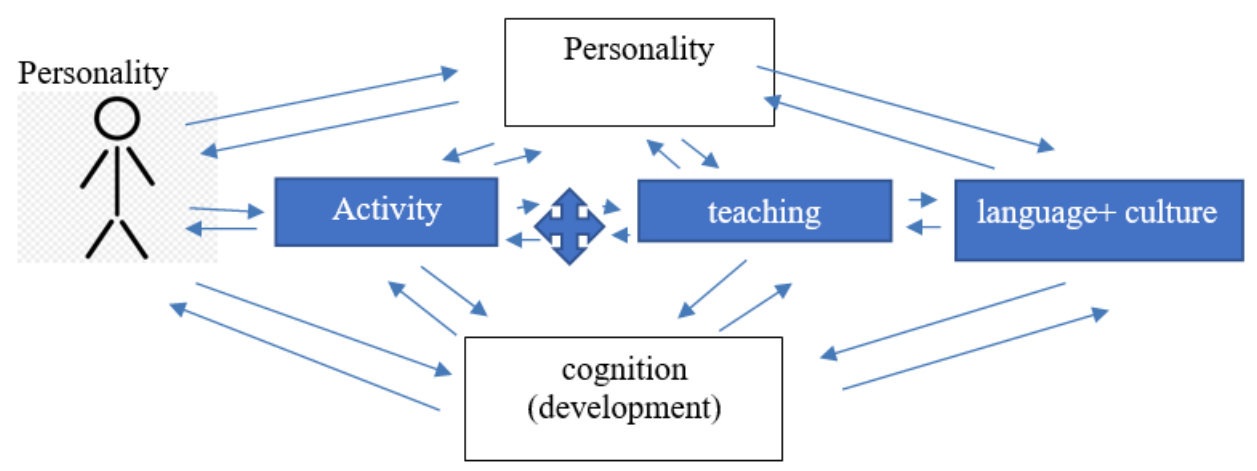

Fig. 1. Axiological bases of professional training of a foreign language teacher.

\section{Discussion}

The developed model of professional training of a foreign language teacher is epistemological in nature, since in real life and in the real pedagogical process, the student's personal potential is an integral personal construct. Within the framework of this article, this construct is divided into components that make up the personal and professional potential of the future foreign language teacher of the primary school for epistemological, i.e. research purposes. This approach, as well as the orientation towards the goals of 
primary foreign language education, allows for a more clear and structured definition of the content of training a professional foreign language teacher of primary school. We also emphasize that in the process of professional training of future teachers of foreign languages, such an approach requires to focus attention not only and not so much on the communicative sphere of the student's personality. The objects of pedagogical influence should also be its value-semantic, motivational, cognitive and, which is especially important, emotional and sensory spheres, i.e. those spheres that are especially sensitive to such categories as the attitude of the individual to the activity he is mastering in the target language and future profession, to himself and the world around him, his motives and personal positions. And this, in turn, requires the involvement of active types of activity that would exercise the future teacher not only, for example, in language, but also in moral assessments and, which is especially important, in moral actions, including in relation to the future profession. It is also necessary to actively pursue access to a real linguo-ethno-sociocultural and professionally-oriented context with its linguo-ethno-socio-cultural nuances and problems [3]. And first of all, access to a polycultural and multilingual real educational space, an educational environment that has lost its bipolar essence (native language foreign language, native culture - culture of the country of the target language), since a modern person at any age constantly exists in a real intercultural dialogue. Thus, the professionalism of a FL teacher for primary school is the result of the integration of his communicative, sociocultural, and social experience, as well as the experience of creative activity in the course of studying FL and the technologies for teaching it to younger schoolchildren, the experience of implementing emotional and value relationships to oneself, to the world of one's native culture and the world of culture of another people, future profession.

\section{Conclusions}

Despite the fact that the training of specialists capable of teaching the foreign language to primary schoolchildren has been conducted in our country since the $90 \mathrm{~s}$ of the last century, and since that time a significant number of works have been published, and a number of studies have been carried out in the field of early foreign language education, determining the conditions for improving the quality of professional training of personnel for preschool institutions and primary schools, the process of the required training cannot be considered effective, which also affects the effectiveness of the achievement of educational results by schoolchildren.

The personal developmental context of children's mastering of foreign language as a cultural phenomenon makes it necessary to update the training of specialists who are able to manage the foreign language education of primary schoolchildren and ensure their interconnected moral, speech, cognitive and communicative development. This means that only a teacher who is guided in his activity by the values of humanistic pedagogy and who is able to provide children with their moral formation when they master the foreign language can effectively teach, develop and educate children. The latter assumes:

firstly, the understanding by future teachers of foreign languages of the essence of the upbringing process as a process of the moral development of children;

secondly, the formation of students' ability to design this process, taking into account the specifics and capabilities of primary school age.

The personality-oriented dominant of modern education requires further research related to the concretization of the content of the axiological aspect of foreign language education in a pedagogical university, with the formation of the future teacher's ability to intercultural communication, coupled with the development of both his moral personal qualities and the 
ability to form moral values in children: civic identity, patriotism, pride in their culture, love for their native language, and interest in the studied language and other culture.

Thus, the axiological dimension of modern professional pedagogical education orients the content of professional linguistic education towards value orientations, humanistic values, motives of the future teacher of foreign language for primary school, towards his individually motivated attitude towards his (self)education and future professional activity, towards the ability to interact in socially determined and professional situations, on the recognition of the relevance of the values of humanity as the ideal of humanism, towards the culture of communicative behavior. At the same time, such categories as spirituality and morality should be recognized as a kind of reference points of this formation in its axiological dimension. It is these categories that should be regarded as linguistic values, and at the same time act as strategic target guidelines for the training of a foreign language teacher, determining the specifics of its content and the specifics of future professional activities.

\section{References}

1. N.D. Galskova, Foreign languages at school 8, 4-10 (2019)

2. Z.N. Nikitenko, Methodical system of mastering a foreign language at the initial stage of school education. Diss. for a degree of Doctor of Pedagogical Sciences (Moscow, Moscow State Pedagogical University, 2015)

3. Psychology and pedagogy of contextual education: Collective monograph (M., SPb, Nestor-History, 2018)

4. G.V. Rogova, T.E. Sakharova, Methodical mosaic 6, 78-82 (1990)

5. V.V. Ryzhov Personality: creativity and spirituality: monograph (SPb, Publishing house of the Saint Petersburg Christian University, 2012)

6. K.N. Khitrik, Linguodidactic concept of teaching the culture of foreign language speech communication in a special language university. Diss. for a degree of Doctor of Pedagogical Sciences (M., 2000) 